\title{
TINGKAT KELAYAKAN USAHATANI PADI HIBRIDA DI KECAMATAN KERUAK KABUPATEN LOMBOK TIMUR
}

\author{
${ }^{1}$ RIZAL AHMADI, ${ }^{2}$ SIROJUDDIN \\ ${ }^{1}$ Dosen Fakultas Pertanian-Universitas Gunung Rinjani \\ ${ }^{2}$ PPL Desa Senyiur Kecamatan Keruak \\ Emaill : ahmadirizal1965@gmail.com \\ Email : sirojuddin607@yahoo.co.id
}

\begin{abstract}
ABSTRAK
Penggunaan varietas padi hibrida saat ini merupakan salah satu cara meningkatkan produktivitas padi secara nasional, Akan tetapi masih banyak masyarakat yang belum mengenal padi hibrida, sehingga masyarakat tetap tergantung pada varietas padi local. Padi hibrida ini produktivitasnya mampu mencapai 12 ton/Ha gabah kering panen dimana produksinya lebih tinggi jika dibandingkan dengan padi local yang hanya mencapai 6 sampai 7 ton/ha gabah kering panen.. Tujuan dari penelitian ini adalah untuk a) mengetahui besarnya pendapatan yang diperoleh petani pada usahatani padi hibrida di kecamatan Keruak dan, b) mengetahui kelayakan usahatani padi hibrida di kecamatan Keruak. Adapun metode yang digunakan dalam penelitian ini adalah metode deskriptif dengan teknk wawancara dalam pengambilan data di lapangan.Sedangkan hasil penelitian yang diperoleh biaya yang dkeluarkan sebesar Rp. 20.180.928,/LLG atau Rp. 22.760.446 / ha. Dengan produksi sebesar $8.067 \mathrm{Kg} / \mathrm{LLG}$ atau $9.098 \mathrm{Kg}$ perhektar dengan nilai produksi sebesar Rp. 32.268.000/LLG atau Rp. 36.392.000/Ha Sedangkan rata-rata pendapatan yang diterima petani padi hibrida Rp 12.087.072/LLG atau Rp 13.631.554/Ha. Dari hasil analisis menunjukan bahwa R/C Ratio 1,6 berarti usaha tani padi hibrida layak diusahakan
\end{abstract}

Kata Kunci : Pendapatan, R/C Ratio, Padi Hibrida

\begin{abstract}
The use of hybrid rice varieties is currently one way to increase rice productivity nationally. However, there are still many people who are not familiar with hybrid rice, so people still depend on local rice varieties. This hybrid rice productivity is able to reach 12 tons/ha of harvested dry grain where the production is higher when compared to local rice which only reaches 6 to 7 tons/ha of dry harvested grain. The purpose of this study is to a) determine the amount of income earned by farmers on hybrid rice farming in Keruak subdistrict and, b) knowing the feasibility of hybrid rice farming in Keruak sub-district. The method used in this study is a descriptive method with interview techniques in data collection in the field. While the results of the study obtained that the costs incurred were Rp. 20,180,928,/LLG or Rp. 22,760,446/ha. With a production of $8,067 \mathrm{Kg} / \mathrm{LLG}$ or $9,098 \mathrm{Kg}$ per hectare with a production value of $\mathrm{Rp}$. 32,268,000/LLG or Rp. $36,392,000 / \mathrm{Ha}$ While the average income received by hybrid rice farmers is Rp. 12,087,072/LLG or Rp. $13,631,554 / \mathrm{Ha}$. The results of the analysis show that the R/C Ratio of 1.6 means that hybrid rice farming is feasible
\end{abstract}

Keywords: Income, R/C Ratio, Hybrid Rice 


\section{PENDAHULUAN}

Provinsi Nusa Tenggara Barat adalah salah satu yang mempunyai tanah yang sangat subur dan produktif sehingga sangat mendukung dalam melakukan kegiatan pertanian. Akan tetapi kondisi saat ini tanah kita sudah mulai rusak yang diakibatkan oleh penggunaan pupuk yang berlebihan dan tanam yang terus menerus sehingga membuat tanah kehilangan unsur haranya. Oleh karna itu pemerintah telah menerapkan berbagai sistem untuk mengembalikan kesuburan tanah tersebut dengan mengeluarkan berbagai macam kebijakan dan teknologi baru secara bertahap dengan harapan untuk memajukan pembangunan di bidang pertanian serta neningkatkan kesejahtraan petani (Mosher 1991).

Pembangunan pertanian yang dilaksanakan bertujuan untuk meningkatan hasi produksi pertanian, khususnya dalam pemenuhan pangan dan gizi dalam rangka meningkatkan taraf hidup petani dan kesejahteraan masyarakat. Usaha dalam memenuhi bahan pangan tersebut diarahkan keberbagai jenis komoditas tanaman pangan padi, palawija, dan hortikultura (Sunaryo dan Risminandar 1994).

Kementerian pertanian menyatakan produksi tanaman padi mengalami penurunan dari tahun 2017 mencapai 81 juta ton, dan pada tahun 2018 mencapai 80 juta ton yang berarti ada selisih penurunan sekitar 1 juta ton. Hal ini disebabkan perubahan iklim yang terjadi di Indonesia sehingga terjadi gagal panen.

Salah satu strategi dalam upaya peningkatan produktivitas usahatani padi adalah penerapan panca usahatani yang meliputi penggunaan bibit unggul, pengolahan tanah yang sempurna, pengairan ,pemupukan berimbang dan Pengendalian hama terpadu (Badan Ketahan Pangan dan Penyuluhan Aceh 2009).

Penggunaan varietas padi hibrida saat ini merupakan suatu solusi dalam upaya peningkatan produksi dan produktivitas gabah nasional, Namun sejauh ini masih banyak masyarakat yang belum mengenal padi hibrida, sehingga masyarakat tetap tergantung pada varietas padi non hibrida yang biasanya ditanam secara turun temurun seperti Ciherang, Ciliwung, IR64, Ciugelis,
Membramo, Impari. Akibat ketergantungan pada varietas padi non hibrida produksi padi sulit ditingkatkan, karena rata - rata potensi hasil padi non hibrida berkisar antara 6 sampai 7 ton per hektar (BBPP Tanaman Padi Departemen Pertanian 2009).

Berdasarkan data UPPTP Kecamatan Keruak dan Dinas Pertanian Kabupaten Lombok Timur tahun 2019, diketahui bahwa luas lahan yang ditanami komoditas padi di Kecamatan Keruak mengalami fluktuasi dimana pada tahun 2016 luas lahan yang ditanami padi sebanyak 2.244 hektar, pada tahun 2017 luas lahan yang ditanami padi meningkat menjadi $2 . .591$ hektar, pada tahun 2018 luas lahan ditanami padi meningkat menjadi 2.638 hektar, sedangkan pada tahun 2019 luas lahan menurun menjadi 2.591 hektar.

Sedangkan produksi gabah kering panen yang ada di Kecamatan keruak pada tahun 2016 sebanyak 13.517,40 ton, pada tahun 2017 produksi gabah kering panen sebanyak 15.576,80 ton, pada tahun 2018 produksi gabah kering panen sebanyak $16.054,80$ ton, sedangkan pada tahun 2019 produksi gabah kering panen sebanyak $15.849,90$ ton.

Adapun produtivitas gabah kering panen yang ada di Kecamatan Keruak pada tahun 2016 sebanyak 5,90 ton per hektar, pada tahun 2017 produktivitas gabah kering panen sebanyak 5,95 ton per hektar, pada tahun 2018 produktivitas gabah kering panen sebanyak 5.94 ton/Ha, dan tahun 2019 produksi sebanyak 5,96 ton/Ha.

Padi hibrida mampu berproduksi sampai dengan 12 ton/Ha gabah kering karena tanaman ini memerlukan perawatan yang ekstra hati - hati, karena mudah terserang hama dan penyakit, sehingga membutuhkan biaya yang lebih besar dari usaha tani padi non hibrida (BBPP Tanaman Padi Departemen Pertanian 2019)

\section{TUJUAN PENELITIAN}

1. Mengetahui bearnya pendapatan petani padi hibrida di Kecamatan Keruak

2. Untuk mengetahui kelayakan usahatani padi hibrida di kecamatan Keruak Kabupaten Lombok Timur. 


\section{METODE PENELITIAN}

\section{Metode dan Tehnik Pengumpulan Data}

Metode deskriptif yang digunakan dalam penelitian yaitu metode yang bertujuan untuk memecahkan masalah yang ada pada waktu sekarang dengan cara mengumpulkan data, kemudian menyusun data, menganalisis data, dan kemudian menarik kesimpulan (Nazir, 2013).

Tehnik survey digunakan untuk pengumpulan data dengan mengambil sebagian dari populasi dan digunakan untuk menentukan sifat serta ciri dari populasi dengan wawancara langsung dengan berpedoman pada daftar pertanyaan (Sugiyono, 2009).

\section{Penentuan Lokasi Penelitian}

Penelitian dilaksanakan di Kecamatan Keruak dengan mengambil tiga desa sebagai lokasi penelitian secara Purposive Sampling (secara sengaja) yaitu desa Batu Putik, Pijot Utara dan desa Pijot, karena 3 desa tersebut merupakan jumlah petani dan produksi padi hibrida yang terbanyak di kecamatan Keruak. (UPPTP Kecamatan Keruak, 2019)

\section{Penentuan Responden}

Petani yang dijadikan sebagai responden dalam penelitian ini adalah petani sawah. Sedangkan penentuan jumlah responden dilakukan dengan Quota Sampling yaitu 30 orang petani sebagai responden. Penentuan jumlah responden secara Proporsional Random Sampling, sebagai berikut :

$\begin{array}{ll}\text { Desa Pijot Utara } & n= \\ \frac{137}{360} \times 30=11 \text { Orang } & \\ \text { Desa Batu Putik } & n= \\ \frac{150}{360} \times 30=13 \text { Orang } & \\ \text { Desa Pijot } & n= \\ \frac{73}{360} \times 30=6 \text { Orang } & \end{array}$

\section{Jenis dan Sumber Data}

Jenis data dalam penelitian ini yaitu data kualitatif dan kuantitatif. Data kualitatif berbentuk kata, kalimat, narasi, gerak tubuh, bagan gambar dan foto, sedangkan data kuantitatif berbentuk angka atau data kualitatif yang diangkakan (Sugiyono, 2018)

Sumber data ada dua yaitu data primer yang berasal dari hasil wawancara dengan responden dan data skunder yang bersumber dari dinas dan instansi yang terkait dengan penelitian.

\section{Variabel Yang diukur}

a. Biaya Tetap (Fixed Cost), adalah biaya yang tidak dipengaruhi oleh besar kecilnya produksi yang dihasilkan, biaya tetap ini mencakup :

1). Lahan pertanian. yang dimaksud dengan lahan adalah sawah tempat kegiatan bertani padi yang diukur dengan satuan hektar (Ha)

2). Penyusutan alat-alat (depresiasi), adalah nilai alat-alat akhir tahun yang dikurangi nilai alat untuk pertama kali dibagi dengan tahun penggunaannya (jangka usia ekonomis alat). yang diukur dengan rupiah

3). Sewa lahan diukur berdasarkan sewa tanah yang dikeluarkan selama produksi dinyatakan dalam satuan rupiah $(\mathrm{Rp})$

4). Pajak tanah dan iuran pengairan, diukur berdasarkan besarnya pajak tanah dan iuran yang dikeluarkan untuk satu kali proses produksi dan dinyatakan dalam satuan rupiah $(\mathrm{Rp})$

b. Biaya Tidak Tetap (Variabel Cost) adalah biaya yang besar kecilnya tergantung dari skala produksi, biaya variabel ini meliputi

1). Biaya sarana produksi (bibit dan pupuk). Yang diukur dengan rupiah

2). Biaya tenaga kerja yakni semua biaya yang digunakan selama proses produksi dan secara fisik dinilai dalam satuan rupiah per hari kerja.

b. Produksi adalah hasil padi yang diperoleh petani dalam satuan kuintal $(\mathrm{Ku})$.

c. Penerimaan Usahatani adalah nilai produksi dari hasil penjualan atau merupakan hasil perkalian antara harga persatuan dengan jumlah produksi yang dihasilkan, dinyatakan dalam rupiah per hektar (Rp/Ha).

d. Pendapatan adalah penerimaan produksi (nilai produksi) yang dikurangi dengan total biaya.

6. Analisis Data

1. Untuk mengetahui total biaya yang digunakan dalam usaha tani ini 
digunakan rumus (Padangaran, 2013) sebagai berikut :

$$
\mathbf{T C}=\mathbf{F C}+\mathrm{VC}
$$

Keterangan :

TC = Total Biaya (Total Cost)

FC = Biaya Tetap (Fixed Cost)

VC = Biaya Variabel (Variable Cost)

2. Untuk mengetahui jumlah pendapatan kotor dan pendapatan bersih dalam usahatani ini digunakan rumus (Rosyidi, 2006)

a. Pendapatan kotor

$$
\mathbf{T R}=\mathbf{Q} \mathbf{X} \mathbf{P}
$$

Keterangan:

TR = Total Revenue (Pendapatan kotor)

$\mathbf{Q}=$ Quantitativ Of Commodity (Jumlah produk yang dihasilkan)

$\mathbf{P}=$ Price of Commodity (Harga produk)

b. Pendapatan bersih

$\mathbf{N R}=\mathbf{T R}-\mathbf{T C}$

Keterangan :

NR = Net Revenue (Pendapatan bersih)

TR = Total Revenue

(Penerimaan kotor)

TC = Total Cost (Total Biaya)

3. Untuk mengetahui layak atau tidaknya home industry terasi udang di Desa Jerowaru digunakan analisis (Shinta, 2011) sebagai berikut :

R/C Ratio = TR/TC

Ketentuan :

- Bila R/C Ratio > 1 maka usahatani padi hibrida di Desa Keruak layak untuk diusahakan.

- Bila R/C Ratio < 1 maka usahatani padi hibrida di Desa Keruak tidak layak untuk diusahakan.

- Bila R/C Ratio = 1, berarti Break Event Point maka usahatani padi hibrida di Desa Keruak mencapai titik impas.

\section{HASIL DAN PEMBAHASAN}

\section{Letak Geografis}

Berdasarkan data BPS (Kecamatan

Keruak Dalam Angka 2019) menunjukkan bahwa kecamatan Keruak merupakan salah satu dari 21 kecamatan yang ada di Kabupaten Lombok Timur dengan luas wilayah 40,49 $\mathrm{km}^{2}$ dengan ketinggian 5 - 30 meter diatas permukaan laut yang terdiri dari 15 ( Lima Belas ) desa dengan batas bagian

Timur : Selat Alas

Barat : Kabupaten Lombok Tengah

Utara : kecamatan Sakra Barat

Selatan : kecamatan Jerowaru

Dengan jarak atau orbitasi dari ibukota provinsi (Kota Mataram) adalah kurang lebih $50 \mathrm{~km}$, sedangkan jarak tempuh dari ibukota kabupaten (Kota Selong) adalah kurang lebih $28 \mathrm{~km}$. Topografi Kecamatan Keruak datar dengan jenis tanah liat vertisol yang cukup berat untuk diolah bagi kepentingan usahatani.

\section{Keadaan Iklim Dan Curah Hujan}

Kecamatan Keruak beriklim tropis yang terdiri dari dua musim yaitu beriklim penghujan (Priode Oktober sampai dengan April) dan musim kemarau (Priode April sampai dengan Oktober). Biasanya hujan mulai turun pada bulan November meskipun curah hujannya tidak merata. Curah hujan rata-rata untuk tahun 2019 di Kecamatan Keruak adalah 869,1 mm dengan jumlah hari hujan 71 hari. (UPPTP Kecamatan Kruak, 2019)

\section{Luas Lahan Dan Penggunaan}

Penggunaan lahan di Kecamatan Keruak sebagian besar didominasi oleh lahan pertanian yaitu sawah seluas $2308 \mathrm{Ha}$ dan kebun/tegalan seluas $456 \mathrm{Ha}$, sedangkan kolam seluas $42 \mathrm{Ha}$ dan lainnya seluas 1347 Ha. Dari semua lahan sawah yang ada pemanfaatan terbesar adalah padi dan tembakau.

Kisaran luas lahan sawah yang paling besar pada kecamatan Keruak dimiliki oleh Desa Batu Putik dengan luas lahan 361 hektar dan luas lahan sawah yang paling sedikit dimilikioleh Desa Tal Luar dengan luas lahan hanya 2 hektar. (Kecamatan Keruak Dalam Angka, 2019)

\section{Umur Petani Responden}

Produktivitas kerja dipengaruhi oleh umur tenaga kerja karena semakin lanjut usia seorang semakin menurun produktivitas kerja yang dihasilkan. Hasil penelitian menunjukkan bahwa umur petani padi hibrida 35 sampai dengan 65 tahun seperti table berikut : 
Vol. 10. No.1. Tahun 2020

Tabel 1. Umur Petani Padi Hibrida Di Kecamatan Keruak Lombok Timur Tahun 2019

\begin{tabular}{|c|c|c|c|}
\hline \multirow[b]{2}{*}{ No } & \multicolumn{3}{|c|}{ Petani Padi Hibrida } \\
\hline & Umur (Tahun) & Jumlah Petani & Persentase (\%) \\
\hline 1 & $33-38$ & 5 & 16,7 \\
\hline 2 & $39-44$ & 5 & 16,7 \\
\hline 3 & $45-50$ & 12 & 40 \\
\hline 4 & $51-56$ & 4 & 13,3 \\
\hline 5 & $57-62$ & 3 & 10 \\
\hline 6 & $63-68$ & 1 & 3,3 \\
\hline & Jumlah & 30 & 100 \\
\hline
\end{tabular}

Sumber : Data Primer Diolah 2020

Berdasarkan tabel 1 diatas dapat dijelaskan bahwa, umur petani padi hibrida terbanyak antara umur 45 sampai 50 tahun sebanyak 12 orang (40\%). Umur 15 tahun hingga 65 tahun tergolong dalam usia produktif. (Simanjuntak 1985), Berdasarkan kriteria ini berarti semua petani tergolong dalam usia produktif yang memiliki kemampuan kerja baik mental maupun fisik untuk mengelola usahataninya.

\section{Tingkat Pendidikan Petani Responden}

Pada tabel 2 di bawah ini dapat dijelaskan, bahwa tingkat pendidikan dari masing-masing petani responden sangat bervariasi. Persentase terbanyak pada petani padi hibrida yaitu pada tingkat SD sebanyak 17 orang $(56,7 \%)$.

Tabel 2. Tingkat Pendidikan Petani Responden Pada Usahatani Padi Hibrida Di Kecamatan Keruak Kabupaten Lombok Timur 2019

\begin{tabular}{|c|l|c|c|}
\hline \multirow{2}{*}{ No } & \multirow{2}{*}{ Tigkat Pendidikan } & \multicolumn{2}{|c|}{ Usahatani Padi Hibrida } \\
\cline { 3 - 4 } & & Jumlah Petani & Persentase (\%) \\
\hline 1 & Tamat SD & 17 & 56,7 \\
2 & Tamat SMP & 5 & 16,7 \\
3 & Tamat SMA & 5 & 16,7 \\
4 & Tamat P T & 3 & 10 \\
\hline & Jumlah & 30 & 100 \\
\hline
\end{tabular}

Sumber : Data Primer Diolah 2020

Berdasarkan tabel 2 tersebut diatas dapat diketahui bahwa tingkat pendidikan petani di daerah penelitian tergolong rendah karena didominasi oleh tingkat pendidikan SD, Berarti petani padi hibrida hanya mengikuti cara bercocok tanan sesuai dengan apa yang diwariskan secara turun menurun

\section{Tanggungan Keluarga Petani}

Tabel 3. Distribusi Jumlah Tanggungan Keluarga Petani Responden Pada Usahatani Padi Hibrida Di Kecamatan Keruak Kabupaten Lombok Timur 2019

\begin{tabular}{|c|c|c|c|}
\hline \multirow{2}{*}{ No } & \multicolumn{3}{|c|}{ Petani Padi Hibrida } \\
\cline { 2 - 4 } & Tanggungan (orang) & Jumlah petani & Persentase (\%) \\
\hline 1 & $1-2$ & 8 & 26,7 \\
2 & $3-4$ & 20 & 66,7 \\
3 & $>5$ & 2 & 6,7 \\
\hline \multicolumn{2}{|c|}{} & 30 & 100 \\
\hline
\end{tabular}

Sumber: Data Primer Diolah 2020 
Vol. 10. No.1. Tahun 2020

Dari tabel 3 diatas menunjukkan, bahwa rata-rata jumlah tanggungan petani padi hibrida terbanyak dengan jumlah tanggungan $3-4$ orang yaitu sebanyak 20 orang $(66,7 \%)$, Artinya petani padi hibrida tergolong dalam keluarga menengah, ini juga mencerminkan adanya sumber tenaga kerja di dalam keluarga petani. Hal ini akan berpengaruh tehadap kelancaran dalam mengelola usahatainya dan memperkecil biaya tenaga kerja yang dikeluarkan dalam berusahatani.

\section{Luas Lahan Garapan Petani Responden}

Besar kecilnya produksi yang pada akhirnya juga dapat menentukan besar kecilnya pendapatan pada usahatani salah satunya ditentukan oleh Luas lahan garapan petani, seperti table berikut..

Tabel 4. Distribusi Luas Lahan Garapan Petani Responden Pada Usahatani Padi Hibrida Di Kecamatan Keruak Kabupaten Lombok Timur Tahun 2019

\begin{tabular}{|c|c|c|c|}
\hline \multirow{2}{*}{ No } & \multicolumn{3}{|c|}{ Petani Padi Hibrida } \\
\cline { 2 - 4 } & Luas Lahan Garapan (Ha) & Jumlah Petani & Persentase (\%) \\
\hline 1 & $0,40-0,64$ & 8 & 26,7 \\
2 & $0,65-0,89$ & 4 & 13,3 \\
3 & $0,90-1,14$ & 13 & 43,3 \\
4 & $1,15-1,39$ & 1 & 3,3 \\
5 & $140-1,64$ & 3 & 10 \\
6 & $1,65-1,90$ & 1 & 3,3 \\
\hline \multicolumn{2}{r|}{} & 30 & 100 \\
\hline
\end{tabular}

Sumber : Data Primer Diolah 2020

Berdsarkan table tersebut untuk luas lahan garapan petani padi hibrida terbanyak yaitu pada kisaran 0,90 - 1,14 sebanyak 13 orang $(43,3 \%)$.. Berdasarkan penggolongan petani menurut Sayogyo (1977) maka, petani padi hibrida sebagian besar tergolong petani menengah ,

\section{Biaya Tetap (Fixed Cost)}

Tabel 5. Rata-Rata Biaya Tetap (Fixed Cost) PerLuas Garapan Dan Per Hektar Usahatani Padi Hibrida Di Kecamatan Keruak Kabupaten Lombok Timur Tahun 2019

\begin{tabular}{|c|c|c|c|}
\hline No & Jenis Biaya Tetap & Rupiah/LLG & Rupiah/LLG \\
\hline 1 & Sewa Tanah & 2.955 .55 & 3.333 .333 \\
\hline 2 & Pajak Tanah & 43.766 & 49.360 \\
\hline 3 & Pengairan & 283.733 & 320.000 \\
\hline 4 & Penyusutan Alat & 55.867 & 63.008 \\
\hline 5 & Upah Pengelola & 3.226 .600 & 3.639 .023 \\
\hline \multicolumn{2}{|r|}{ Jumlah } & 6.565 .522 & 7.404 .724 \\
\hline No & $\begin{array}{c}\text { Jenis Biaya Tidak Tetap Sarana } \\
\text { Produksi }\end{array}$ & & \\
\hline 1 & Benih & 1.483 .667 & 1.673 .308 \\
\hline \multirow[t]{6}{*}{2} & Pupuk : & & \\
\hline & -Urea & 479.500 & 540.789 \\
\hline & -SP36 & 300.667 & 339.098 \\
\hline & - NPK & 520.000 & 586.466 \\
\hline & - Organik & - & \\
\hline & $-\mathrm{ZA}$ & 40.000 & 45.113 \\
\hline 3 & Pestisida & 603.167 & 680.263 \\
\hline \multicolumn{2}{|r|}{ Jumlah } & 3.427 .000 & 3.865 .038 \\
\hline
\end{tabular}



Vol. 10. No.1. Tahun 2020

\begin{tabular}{|c|l|r|r|}
\hline No & \multicolumn{2}{|c|}{$\begin{array}{l}\text { Jenis Biaya Tidak Tetap Tenaga } \\
\text { Kerja (Rp) }\end{array}$} & \\
\hline 1 & -Pengolahan Lahan & 1.970 .733 & 2.222 .632 \\
2 & -Biaya Penyemaian & 146.000 & 164.662 \\
3 & -Biaya Penanaman & 1.169 .333 & 1.318 .797 \\
4 & -penyiangan & 740.000 & 834.586 \\
5 & -Pemupukan & 296.667 & 334.586 \\
6 & -Penyemprotan & 380.000 & 428.571 \\
7 & -Panen & 4.802 .325 & 5.416 .156 \\
& & & \\
\hline \multicolumn{2}{|c|}{ Jumlah } & 9.505 .058 & 10.719 .991 \\
\hline
\end{tabular}

Sumber : Data Primer Diolah 2020

Tabel 5 diatas terlihat bahwa total biaya tetap petani padi hibrida yaitu $\mathrm{Rp}$. 6.565.522,- Perluas garapan atau Rp. 7.404.724,- per hektar.

Perhitungan sewa lahan dihitung dengan cara membagi sewa lahan per tahun Rp.10.000.000 dengan 12 (dua belas) dan dikali dengan lamanya waktu budidaya atau proses produksi.

Iuran pengairan yang dikeluarkan petani responden merupakan biaya yang diberikan kepada pekasih yang dihitung berdasarkan luas lahan garapan yaitu $\mathrm{Rp}$. 2000 - 4000 per are atau Rp. 200.000400.000 per hektar.

Penyusutan alat dihitung dengan cara membagi harga barang dengan umur ekonomis yang selanjutnya dibagi 12 (dua belas) bulan dan dikali 4 (empat), karena waktu usahatani padi sawah selama 4 (empat) bulan.

Demikian halnya dengan pajak, penghitungan pajak juga dilhitung dengan cara membagi total pajak pertahun dengan 12 (dua belas) dan dikali dengan lamanya waktu budidaya atau proses produksi.

Gaji pengelola dihitung dengan cara mengalikan total nilai produksi atau penerimaan dengan $10 \%, 10 \%$ merupakan ketentuan yang biasa berlaku pada masyarakat.

Perhitungan bunga modal juga dilhitung dengan cara membagi bunga modal pertahun dengan 12 (dua belas) dan dikali dengan lamanya waktu budidaya atau proses produksi. Persentase bunga bank yaitu sebesar $10,5 \%$ per tahun.

Berdasarkan tabel 5 diatas diperoleh rata-rata biaya saprodi sebesar Rp.
3.427.000,- perluas lahan garapan atau Rp. 3.865.038,- perhektar, Adapun rincian besarnya biaya yang dikeluarkan petani responden pada masing-masing komponen biaya tidak tetap adalah sebagai berikut:

a. Benih

Benih merupakan salah satu faktor yang menentukan tinggi rendahnya produksi. Semakin unggul benih yang digunakan semakin tinggi produksi yang dihasilkan. Dari segi pemilihan ternyata sebagian besar menggunakan benih unggul, yang harganya relatif lebih mahal dengan kebutuhan per hektar $17 \mathrm{~kg} / \mathrm{Ha}$ pada usahatani padi hibrida, b. Pupuk

Pupuk adalah bahan yang ditambahkan kedalam tanah untuk menyediakan unsur-unsur esensial bagi pertumbuhan tanaman (Fort, 1988). Pupuk yang digunakan oleh petani padi hibrida pada lokasi penelitian yaitu Urea $258 \mathrm{Kg} / \mathrm{Ha}$, NPK $244 \mathrm{Kg} / \mathrm{Ha}$, SP-36 sebanyak $154 \mathrm{Kg} / \mathrm{Ha}$ dan ZA $30 \mathrm{Kg} / \mathrm{Ha}$, dosis pupuk yang digunakan masih jauh dibawah rekomendasi Badan litbang Pertanian yaitu Urea $300 \mathrm{Kg} / \mathrm{H}$, NPK $300 \mathrm{Kg} / \mathrm{Ha}$, SP36 sebanyak $100 \mathrm{Kg} / \mathrm{Ha}$. Harga pupuk Urea Rp.2.100,-/Kg, NPK Rp. $2.400,-/ \mathrm{Kg}$, TSP Rp. $2.200,-/ \mathrm{Kg}, \mathrm{ZA} \mathrm{Rp}$. $1.500,-/ \mathrm{Kg}$.

\section{c. Pestisida}

Jenis pestisida yang digunakan petani padi hibrida adalah jenis insektisida seperti virtako, metindo, montap, regent, prevaton, dan furadan. Biaya pestisida pada usaha tani Padi hibrida sebesar Rp. 603.167,-/luas lahan garapan atau sebesar Rp. 680.263/ha.

d. Tenaga Kerja 
Vol. 10. No.1. Tahun 2020

Tenaga kerja adalah biaya yang dikeluarkan petani responden untuk membayar upah tenaga kerja. Upah tenaga kerja tersebut meliputi biaya untuk pembibitan, pengolahan tanah, penyemaian, penanaman, penyiangan, pemupukan, penyemprotan dan panen..

Biaya pengolahan lahan dihitung dengan cara menjumlahkan antara biaya pembajakan lahan dan perbaikan pematang dengan upah tenaga kerja pada waktu pembajakan. Biaya penanaman dihitung berdasarkan jumlah tenaga kerja dikali upah tenaga kerja per orang perhari.

Biaya penyiangan dihitung dengan mengalikan jumlah tenaga kerja dengan upah kerja perhari, petani responden melakukan penyiangan 1 hingga 2 kali, sehingga total biaya penyiangan dihitung dengan menambahkan biaya penyiangan pertama dengan biaya penyiangan kedua.

Biaya pemupukan relatif kecil karena tenaga kerja yang dibutuhkan sedikit. Biaya

Tabel 6. Rata-Rata Biaya Produksi Pada Usahatani Padi Hibrida Di Kecamatan Keruak Tahun 2019.

\begin{tabular}{|l|l|r|r|}
\hline No & Komponen Biaya & \multicolumn{1}{|c|}{ Rp/LG } & \multicolumn{1}{c|}{ Rp/Ha } \\
\hline 1 & Biaya Tetap & 6.565 .522 & 7.404 .724 \\
2 & Biaya Tidak Tetap & 12.932 .058 & 14.585 .028 \\
3 & Bunga Modal & 683.348 & 770.694 \\
\hline \multicolumn{2}{|c|}{ Jumlah } & 20.180 .928 & 22.760 .446 \\
\hline
\end{tabular}

Sumber : data Primer Diolah 2020

\section{Produksi, Nilai Produksi, Total Biaya, Pendapatan dan B/C Rasio.}

Tabel 7. Rata-Rata Produksi, Nilai Produksi, Total Biaya, Pendapatan dan R/C Rasio Usahatani Padi Hibrida Di Kecamatan Keruak Kabupaten Lombok Timur 2019

\begin{tabular}{|l|l|r|r|}
\hline No & \multicolumn{1}{|c|}{ Usahatani Padi } & Perluas Garapan & \multicolumn{1}{|c|}{ Perhektar } \\
\hline 1 & Produksi (Kw) & 80,67 & 90,98 \\
2 & Harga (Rp/Kg) & 4000 & 4000 \\
3 & Nilai Produksi (Rp) & 32.268 .000 & 36.392 .000 \\
4 & Total Biaya (Rp) & 20.180 .928 & 22.760 .446 \\
5 & Pendapatan (Rp) & 12.087 .072 & 13.631 .554 \\
6 & R/C Ratio & 1,60 & 1,60 \\
\end{tabular}

Sumber : Data Primer Diolah

Berdasarkan Tabel 7 diatas diketahui bahwa produksi padi hibrida yaitu 8.067 $\mathrm{Kg} / \mathrm{LLG}$ atau $9.098 \mathrm{Kg} / \mathrm{Ha}$ dengan penerimaan sebesar Rp. 32.268 .000 perluas garapan atau Rp. 36.392 .000 per hektar.

Tingginya produksi padi hibrida disebabkan karena padi hibrida anakannya lebih banyak, malainya lebih panjang, batangya lebih besar dan buahnya lebih bernas sehingga mengakibatkan produksi padi hibrida lebih tinggi

Sedangkan rata-rata pendapatan yang diterima petani padi hibrida Rp 12.087.072/llg atau Rp 13.631.554/Ha. 
Vol. 10. No.1. Tahun 2020

Adapun dari hasil analisis menunjukan bhwa R/C Ratio 1,6 yang berarti bahwa setiap pengeluaran Rp. 1 akan memperoleh penerimaan Rp. 0,6 atau kata lain setiap biaya yang di keluarkan dalam usahatani padi hibrida sebesar Rp. 1000 akan mendapatkan penerimaan sebesar Rp. 600 sehingga usahatani padi hibrida layak diusahakan di Kecamatan Keruak Kabupaten Lombok Timur.

\section{KESIMPULAN DAN SARAN \\ 1. Kesimpulan}

Berdasarkan hasil penelitian, maka dapat diambil kesimpulan sebagai berikut:

a. Rata-rata pendapatan yang diterima petani padi hibrida Rp 12.087.072 per LLG atau 13.631.554 per Ha

b. Hasil analisis menunjukan nilai $\mathrm{R} / \mathrm{C}$ Rasio sebesar 1,6.. Artinya bahwa usahatani padi hibrida di Kecamatan Keruak layak untuk dikembangkan dan diusahakan oleh petani.

\section{Saran}

Berdasarkan hasil penelitian yang dilaksanakan di Kecamatan Keruak Kabupaten Lombok Timur, terhadap petani responden yang melakukan usahatani padi hibrida disarankan hal-hal sebagai berikut:

a) Pendampingan kepada petani secara berkala agar mendapatkan produksi dan pendapatan yang menguntungkan dari usahatani yang dijalankan.

b) Agar subsidi benih padi hibrida diberikan kepada petani karena harga benih terlalu mahal, agar petani memperoleh produksi tinggi dan memperoleh keuntungan pada usahataninya.

c) Bagi petani yang melaksanakan kegiatan usahatani padi hibrida, hendaknya tetap berkoordinasi dengan penyuluh pertanian.

\section{DAFTAR PUSTAKA}

Ashari dan Rusastra Wayan 2014.Pusat Sosial Ekonomi dan Kebijakan Pertanian.

Aripudin Sahidu, 1987. Pengantar ilmu pertanian. Fakultas Pertanian Unram.
Anonim, 2011 Deskripsi Varietas Padi Badan Litbang (bpadi.litbang.pertanian.go.id)

Pertanian

Anonim, Sinar Tani, Edisi 2-8 Nopember 2011 No.3429 Tahun XLII. PT.Gramedia. Jakarta..

Kaslan A. Tohir, 1983. Seuntai Pengetahuan Tentang Usahatani Indonesia. Bina Aksara Jakarta.

Mosher A. T, 1985, Menggerakkan dan Membangun.Pertanian, LIEM

Mubyarto, 1989, Pengantar Ekonomi Pertanian, LP3ES, Jakarta

Mulyadi, 2015, Pengertian Biaya Produksi dan cara menghitungnya. https://accurate.id/akuntansi/pengertia n-biaya-produksi-dan-cara-hitung

Sayogyo, 1977 Luas Lahan Usaha Tani dan Kesejahteraan Petani: Eksistensi Petani Gurem dan Urgensi Kebijaka Reforma Agraria

Sapoetro, Hadi. 1985. Biaya dan Pendapatan Dalam Usaha tani. Yogyakarta : Gajah Mada Universiti Press.

Simanjuntak, Payama J. 1985. Pengantar Ekonomi Sumber Daya Manusia.

Soemartono, W, 1982. Pengantar Metodelogi Ilmiah, Dasar Dan Teknik Researeh.Tarsito, Bandung . $338 \mathrm{H}$.

Soekartawi, 1985, Ilmu Usahatani, Jakarta

Suproyo, 1992 dalam Helmiana, 2012 Analisa Komparatif Pendapatan Usahatani Padi Sistim Pindah Tanam dan Sistim Tabela

Sugiyono, 2009. Metode Penelitian Bisnis, Penerbit Alfabeta Bandung 